POST-STROKE MOTOR AND FUNCTIONAL EVALUATIONS

\title{
A clinical correlation using Fugl-Meyer assessment scale, Berg balance scale and Barthel index
}

\author{
Roberta de Oliveira', Enio Walker Azevedo Cacho², Guilherme Borges ${ }^{3}$
}

\begin{abstract}
Stroke is one of the major causes of morbidity and mortality. Sequels deriving from this event may lead to motor disability and from mild to severe deficits. In order to better classify sensory-motor dysfunction, balance and ability to perform activities of daily living, quantitative and qualitative evaluation scales have been used. Objective: To correlate the scales Fugl-Meyer assessment scale, Berg balance scale and Barthel index. Twenty subjects with sequel after a single, unilateral stroke in chronic phase ( $>6$ months post ictus) were evaluated for about one hour. Results: Barthel scale was statistically related to the total motor score of Fugl-Meyer assessment $(r=0.597, p=0.005)$. The lower limb section at Fugl-Meyer had positive correlation with Berg scale $(r=0.653, p=0.002)$ and with the balance section of Fugl-Meyer own scale $(r=0.449, p=0.047)$. Both balance scales were correlated one with other $(r=0.555, p=0.011)$. Statistical divergence appeared when Barthel's Index was correlated with Berg's Scale $(r=0.425, p=0.062)$, and it is not statistically significant. Conclusion: The use of both quantitative and qualitative scales was shown to be a good measuring instrument for the classification of the general clinical performance of the patient, especially when positively related joint evaluations are applied.
\end{abstract}

KEY WORDS: Fugl-Meyer assessment scale, Berg balance scale, Barthel index, stroke.

\begin{abstract}
Avaliações motoras e funcionais pós-AVC: correlação clínica usando a escala de desempenho físico de Fugl-Meyer, a escala de equilibrio de Berg e o índice de Barthel

RESUMO - O acidente vascular cerebral (AVC) é reconhecido como uma das maiores causas de morbidade e mortalidade. Seqüelas decorrentes deste evento podem levar a inabilidade motora e déficits leves a graves. Para classificar melhor a disfunção sensitivo-motora, o equilíbrio e as habilidades para as atividades de vida diária, escalas de avaliações quantitativas e qualitativas estão sendo utilizadas. Objetivo: Correlacionar a escala de desempenho físico de Fugl-Meyer, a escala de equilíbrio de Berg e o índice de Barthel. Método: Foram selecionados 20 sujeitos com sequela de um único e unilateral AVC em fase crônica ( $>6$ meses pós ictal), que passaram pelas avaliações por cerca de uma hora. Resultados: A escala de Barthel correlacionou-se com a pontuação motora total de Fugl-Meyer $(r=0,597, p=0,005)$. A seção para membros inferiores de Fugl-Meyer teve correlação positiva com a de Berg $(r=0,653, p=0,002)$ e com a seção de equilíbrio da própria escala de Fugl-Meyer $(r=0,449, p=0,047)$. Ambas as escalas de equilíbrio tiveram correlação entre si $(r=0555, p=0,011)$. A divergência estatística apareceu quando se correlacionou a Escala de Barthel com o Índice de Berg $(r=0,425, p=0,062)$, não sendo estatisticamente significativo. Conclusão: 0 uso de escalas quantitativas e qualitativas mostrou ser um bom instrumento de medida para a classificação do quadro físico geral do paciente, ainda mais quando são aplicadas avaliações em conjunto que se relacionam positivamente.
\end{abstract}

PALAVRAS-CHAVE: escala de desempenho físico de Fugl-Meyer, escala de equilíbrio de Berg, índice de Barthel, acidente vascular cerebral.

Recently evaluation instruments able to design the neurological profile of patients with stroke sequel are being widely publicized. These instruments help health care professionals to measure the impairment level presented by the subject, since sensorial motor, until functional capacities. Some scales are extensively divulged in the rehabilitation environment, such as, for example, Fugl-Meyer Assessment Scale'1, Berg

Physiotherapy and Occupational Therapy Outpatient Unit, University Hospital - State University of Campinas Medical School Hospital, Campinas SP, Brazil (UNICAMP): ${ }^{1}$ Physiotherapist, Master Degree Student; ${ }^{2}$ Physiotherapist, Master in Surgery; ${ }^{3}$ Neurosurgeon, Associate Professor. This research was supported by FAPESP grants 05/51565-1 and CNPq 302189/2004-1.

Received 24 November 2005, received in final form 10 May 2006. Accepted 15 June 2006.

Dra. Roberta de Oliveira - Rua Senador Vergueiro 687 / 133 - 13480-900 Limeira SP - Brasil. E-mail: rofisio@fcm.unicamp.br 
Balance Scale ${ }^{2}$ and Barthel Index ${ }^{3}$. These scales are based on scores and are both valuable qualitative and quantitative instruments, being able to predict the recovery prognosis of these patients ${ }^{4}$. Another advantage would be the possibility of dividing patients into groups according to their level of impairment, in order to make research or even to prescribe a more adequate therapeutic strategy.

Recent studies ${ }^{5}$ have been considering the issue of correlating scales in order to have accuracy about their use in patient's evaluation as a whole person, apart from also focusing on both dichotomy of upper and lower extremity impairments ${ }^{6}$.

The objective of this investigation was to verify the correlations among Fugl-Meyer Assessment Scale (FM), Berg Balance Scale and Barthel Index in poststroke hemiparetic patients. Research Ethical Committee of our Institution (UNICAMP) approved this report.

\section{METHOD}

Twenty patients from both sexes, with their ages ranging from 25 to 69 years of age were selected in a non-probabilistic manner from the Physiotherapy and Occupational Therapy Ambulatory of the University Hospital - UNICAMP. They had a previous history of a single and unilateral stroke, with a minimum of 6 months and a maximum of 15 years since the lesions had occurred and had not presented other associated neurological pathology, including cognitive impairment.

After collecting of personal data, the patients were undergone to a clinical evaluation that had approximately 1 hour duration, using the scales of Fugl-Meyer', Berg ${ }^{2}$ and Barthel $^{3}$. The evaluations were carried out by two experienced physiotherapists, familiarized with the scales (RO, EWAC).

The Fugl-Meyer physical performance scale assesses five dimensions of impairment, including three aspects of motor control, such as the amplitude of joint movement, pain, sensitivity, motor impairment of the upper and lower extremities and balance. The data are scored in an ordinal scale of 3 ( $0=$ no performance; $2=$ complete performance) applied to each item ${ }^{7}$. The total motor score is equal to the classification of the upper limb (UL) plus the lower limb (LL), corresponding to 100 total scores $(U L=66, L L=34)$. The total FM score, including the other items, corresponds to 226 scores in the final sum.

The Berg Balance Scale comprises of 14 tasks where each one receives a score from 0 to 4, according to the patient's performance. The total score for all tasks consists of 56 scores, being from 0 to 20 considered a poor balance and from 40 to 56 , a good balance 2 .

The Barthel Index assesses activities related to clothing, nourishment, personal hygiene and transfers, each item receiving a score of $0,5,10$ or 15 , reaching a total of 100 scores for individuals who are independent to perform Activity Daily Life $(A D L)^{3}$.

In order to describe the sample profile according to the study variables, descriptive statistics of common variables were calculated, including both mean values and standard deviation (SD). Spearman's correlation coefficient was used to analyze the correlation among the numerical scores of the scales. The significance level adopted for the statistical tests was $5 \%(p<0.05)$.

\section{RESULTS}

The mean age of the selected patients was 47.9 years (10.79 SD), with predominance of both male sex $(60 \%)$ and the ischemic type of lesion (75\%). Deficit of the right body prevailed in $60 \%$ of the subjects. The time elapsed after stroke had a mean of 3.63 years ( $3.02 \mathrm{SD})$.

For the clinical scales, in Table is demonstrated both the mean and the standard deviation of the main items evaluated, where it can be seen that in relation to balance, the mean was relatively elevated, although the patients had a mean quite below the normal score concerning the level of motor impairment.

Correlating the total motor score of FM to the Barthel Index, we were able to observe that the correlation was statistically significant $(r=0.597 ; p=0.005)$, showing that the lower the level of motor impairment, the better will be the individual functional capacity (Fig 1).

The level of motor impairment of LL (FM) significantly correlated with the balance scores of Berg ( $r=$ $0.65305 ; p=0.0018)$ (Fig 2) and with the balance section of FM ( $r=0.44872 ; p=0.0472$ ) (Fig 3).

Regarding to the Berg Balance Scale and the balance section of $\mathrm{FM}$, a strong statistical correlation was found between them ( $r=0.55457 ; p=0.0112$ ) (Fig 4).

When the balance scores were separately correlat-

Table. Mean scores in clinical evaluations.

\begin{tabular}{cccccc}
\hline & $\begin{array}{c}\text { Fugl-Meyer } \\
\text { UL and LL (100) }\end{array}$ & $\begin{array}{c}\text { Total } \\
\text { Fugl-Meyer (226) }\end{array}$ & $\begin{array}{c}\text { Balance } \\
\text { Fugl-Meyer (14) }\end{array}$ & $\begin{array}{c}\text { Berg } \\
(56)\end{array}$ & $\begin{array}{c}\text { Barthel } \\
(100)\end{array}$ \\
\hline Mean & 53.35 & 170.50 & 10.80 & 45.65 & 90.75 \\
SD & 28.44 & 31.91 & 1.24 & 9.41 & 5.45 \\
\hline
\end{tabular}

UL, upper limb; LL, lower limb; SD, standard deviation. 


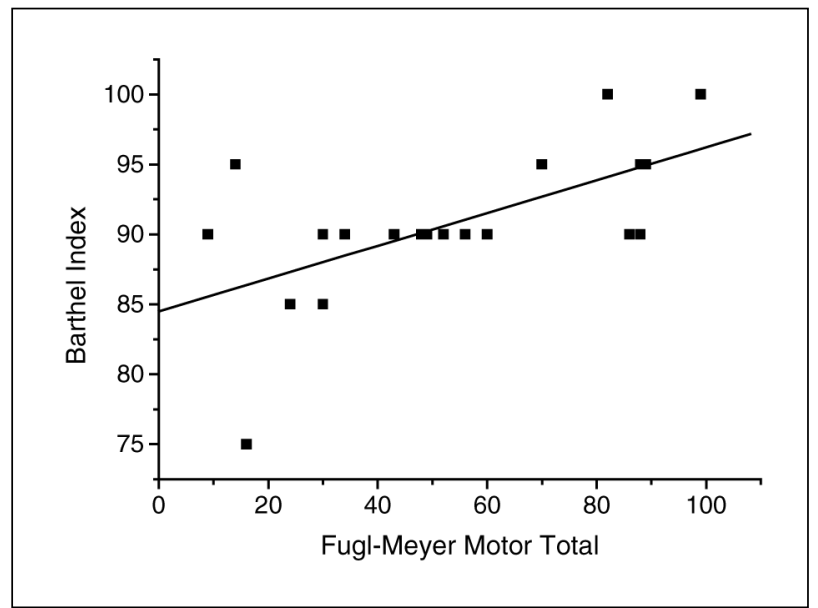

Fig 1. Relationship of the total motor score of the Fugl-Meyer and Barthel Index scales.

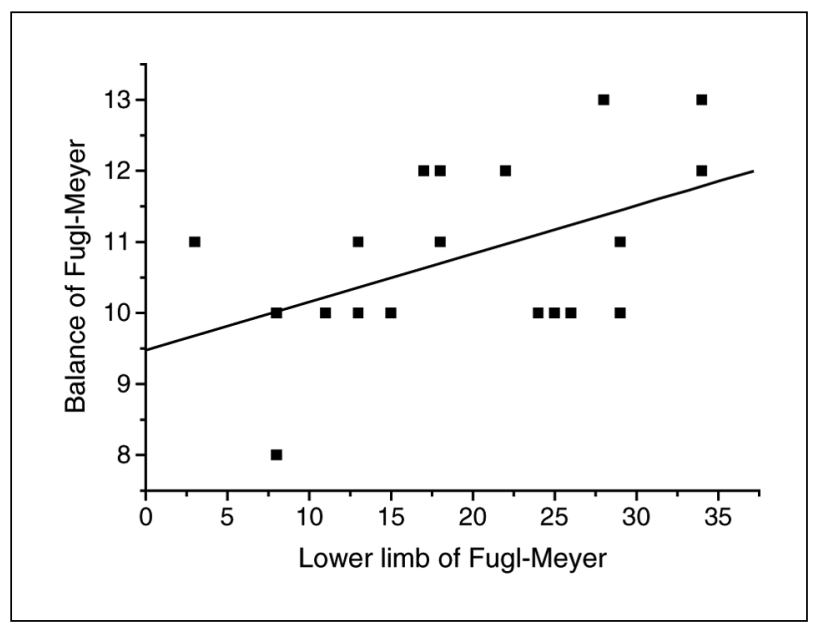

Fig 3. Relationship between the balance and lower limb sections of the Fugl-Meyer Scale.

ed (Berg and balance section of FM) to the level of functional capacity (Barthel), a significant statistical correlation was found only for the balance section of FM (Berg, $r=0.425 ; p=0.062 ; F M, r=0.55006 ; p=$ 0.0120).

\section{DISCUSSION}

The utilization of both quantitative and qualitative scales has been occupying more space in rehabilitation programs, although little is known about its effectiveness, since there are only few studies concerned with correlating evaluations with the neural recovery process ${ }^{8}$. In a research conducted by Ferrucci et al. it was proven that there was improvement of the post-stroke functional performance (Barthel) of subjects, accompanied by a reduction in the level of motor impairment evaluated by the FM scale ${ }^{8}$. Other investigations $^{9}$ also employed the Barthel Index for

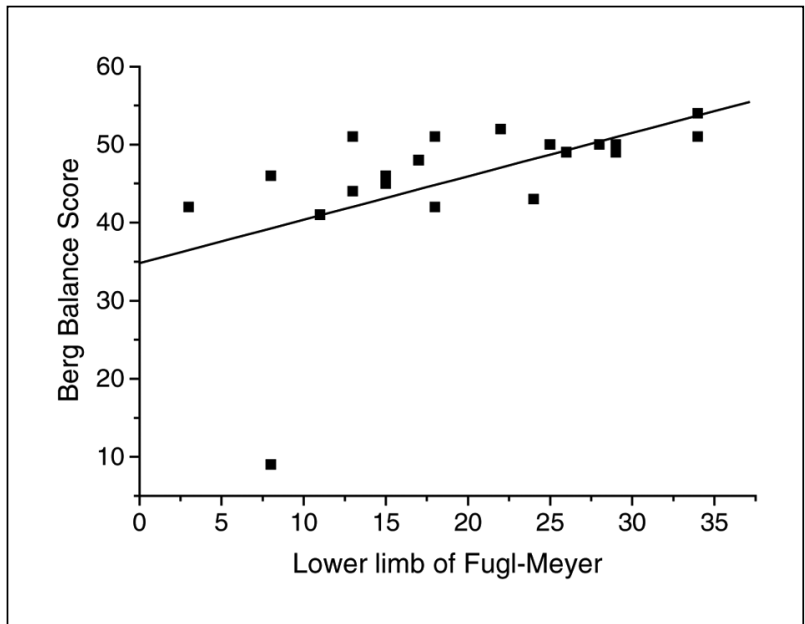

Fig 2. Relationship between the lower limb section of the FuglMeyer Scale and Berg Balance Scale.

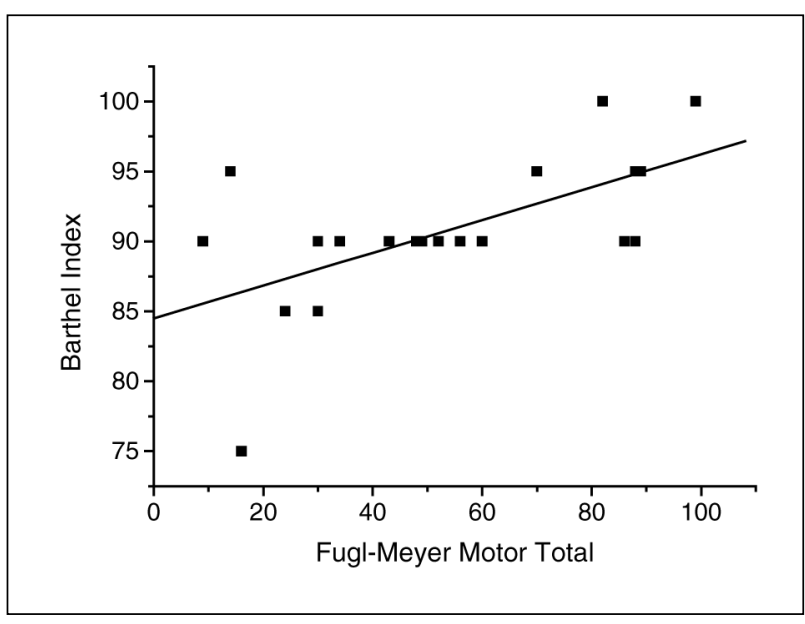

Fig 4. Relationship between the balance section of the FuglMeyer Scale and Berg Balance Scale.

the functional classification of the individual and demonstrated that this scale may be very useful in the standardization of ADL recovery for post-stroke hemiparetic patients. Bohannon et al. reported that the balance scales required research to correlate them with the evolution of motor recovery of post-stroke patients and with the changes related to function ${ }^{10}$. In this study, it was concluded that the ordinal balance evaluation scales are positively correlated with the functional independence measure (FIM) ${ }^{11-14}$.

Level of functional performance versus motor impairment - Ferrucci et al. reported that their study found considerable statistical significance when the FM scale was correlated with the Barthel Index ${ }^{8}$. This information corroborates that one found in this study, where we were able to observe that the Barthel Index was shown to be a statistically significant scale if correlated with the total motor impairment level of FM. 
A strong correlation between motor impairment and functional abilities has been reported ${ }^{11}$. However, two distinct factors contribute to the post-stroke functional recovery: the neurological recovery and the capacity of the patient in transporting and adapting the acquired functional abilities to his/her own environment ${ }^{4}$. One of the ways to investigate the nature of the relationship among different mechanisms is the comparison of clinical changes in the patients through the utilization of validated functional measures $^{12}$. There was no extremity predominance for motor impairment level (UL=51.51\%; $L L=55.88 \%$ ). Other studies also show that UL and LL levels of impairment are similar in motor recovery ${ }^{6,9,13}$.

While changes related to UL and LL are equivalent to the impairment level, there is a great divergence when this impairment is reported in the form of functional abilities. Desrosiers et al. reported that LL has a faster functional recovery rate than UL, although it is still being discussed why during the training period, LL recovery stops, while the UL continues progressing $^{6}$. Scales that depend on the classification from one or more tests, with the total score calculated afterwards (ex. Barthel), are frequently associated to problems in both interpretation and usage ${ }^{4}$, as there may be divergence among the examiners. In addition, scales that present many items to be scored may not be reliable. Wade et al. report that there are many difficulties in measuring the individual functional abilities using only a ADL scale, suggesting that more than a scale should be employed so that one may complete the other ${ }^{4}$. Some suggested scales are: the Functional Independence Measure ${ }^{14}$, Frenchay Arm Test ${ }^{15}$ and Chedoke McMaster ${ }^{16}$, among others.

In this study, we realized that the non-sensitivity of Barthel's scale to assess the isolated extremities, since only two of the evaluated items refer to LL (walking $50 \mathrm{~m}$ and climbing stairs) and the other ones are related to the UL or to transfers.

Regarding to UL graduation in the Barthel Index, Olsen suggests that the functional improvement of patients with severe post-stroke impairment may probably be attributed to the use of compensatory strategies involving the non-paretic limb9. In other words, it does not matter how the patient performs the task; the important thing is for him/her to perform it regardless of the use of compensatory strategies or not.

Level of motor performance versus balance - The relationship between balance and locomotion control has been previously documented ${ }^{10}$ in hemiplegic patients, whose impairment of the automatic pos- tural responses that contribute to sitting and standing balance are directly involved with coordinated and regulated activity of both trunk and limbs ${ }^{17}$. It may be demonstrated in this study, where a moderate relationship was observed between the level of motor impairment and balance. Even with the activation of compensatory strategies, such as the use of stabilizing responses of the non-paretic lower extremity for postural stability as a result of the absence of effective motor patterns with the paretic member ${ }^{12}$, both measures reflect the same impairment profile. This is partly due to the capacity of FM to measure the ability to dissociate and/or segment the movements of the affected limbs, which are essential for the performance of both predictive and proactive balance postural strategies, measured by the Berg Balance Scale and the balance section of FM. Moreover, there are several studies that demonstrate a significant correlation between the balance section of FM and the balance test of Berg with the LL sections of $\mathrm{FM}^{18}$. In this investigation, we observed a good relationship of the LL motor score of FM with the balance test of Berg and also a small relationship with the balance section of FM.

The suggestion from Portney and Watkins should be emphasized, that when the correlation varies from 0.00 to 0.25 , it indicates small or no relationship; between 0.25 and 0.50 , a small degree of relationship; between 0.50 and 0.75 , a moderate to good degree of relationship; and values above 0.75 are taken into consideration for having an excellent degree of relationship ${ }^{19}$.

Balance description and level of motor impairment of the lower extremities present a positive relationship with the level of independent locomotion $^{10,20}$, besides the fact that balance is clearly superior to walking scales in motor impairment description $^{10}$.

Independent locomotion is directly linked to both balance and motricity of the lower extremities ${ }^{20,21}$. In hemiplegic individuals, Bohannon attributes the walking capacity to balance and to their level of motor impairment ${ }^{10}$.

Level of functional capacity versus balance - Some researches have been demonstrating a significant relationship between the measures of balance obtained by means of ordinal scales with the performance of functional tasks, such as the ability to transfer ${ }^{22}$, walk ${ }^{10}$ and climb stairs ${ }^{23}$. In this study, a relationship between the Berg Balance Scale and the Barthel Index could not be observed, which contradicts the fin- 
dings from Berg et al., which reported an intense correlation between the scores obtained in both scales for individuals with stroke ${ }^{2}$. Nichols et al. reported in their study that patients with hemiparesis could learn compensatory strategies to control their balance $^{24}$. The patients can perform functional activities adapting themselves to the imposed conditions given by the impairment. So, at the dressing activity even with the balance compromised, the patient can perform this task lying down and not impeding this one to be performed. The ability of maximum leaning for both sides and forward and also the symmetrical sitting was not strongly correlated to the function $^{24}$.

Other studies report the relationship of balance measures with other functional measures such as FIM $^{14}$, apart from demonstrating great responsiveness and highly significant changes compared with the period of sensory-motor recovery of individuals following stroke ${ }^{10}$. However Nichols et al. reported that even after two (2) weeks into intensive rehabilitation, there were no significant correlation between the postural control measures and FIM scores ${ }^{24}$.

Balance is also an important predictor of sensory-motor and functional rehabilitation results poststroke ${ }^{25}$. Functional improvement may be attributed to the "true" physiological recovery derived from "normal" balance responses and compensatory strategies mainly related to the non-impaired half body or a combination of both ${ }^{12}$. Compensatory motor patterns are adaptive movements that reflect the effect of the lesion, the mechanical characteristics of the motor system and the environmental demands placed on the individual ${ }^{26}$. Clinically, the functional rehabilitation cannot be differentiated from compensatory strategies based only on functional measures ${ }^{12}$, but rather through ordinal balance scales such as the Berg Balance Scale ${ }^{27}$ and from sensory-motor performance measures, such as that of $\mathrm{FM}^{28}$.

In conclusion, quantitative and qualitative measuring scales are good instruments for post-stroke patients evaluation. We observed that the scales, when employed together with others that complement them, make possible to design the general motor performance of the patient in an elucidatory manner. The motor impairment is directly proportional to the correlated variables. Thereby, the more severe the motor impairment is, the larger will be the deficits that will follow the patient, such as balance and ADL abilities, however statistical significance was not found between them.

\section{REFERENCES}

1. Fugl-Meyer AR, Jaasko L, Leyman L, Olsson S, Steglind, S. The poststroke hemiparetic patients: a method for evaluation of physical performance. Scand J Rehab Med 1975; 7:13-31.

2. Berg KO, Maki BE, Williams JI, Holliday PJ, Wood-Dauphinee SL. Clinical and laboratory measures of postural balance in an elderly population. Arch Phys Med Rehab 1992;73:1073-1080.

3. Mahoney FI, Barthel D. Functional evaluation: the Barthel Index. Maryland St Med J 1965;14: 56-61.

4. Wade DT, Langton-Hewer R, Wood VA, Skilbeck CE, Ismail HM. The hemiplegic arm after stroke: measurement and recovery. J Neurol Neurosurg Psychiatry 1983;46:521-524.

5. Valach L, Signer S, Hartmeier A, Hofer K, Steck GC. Chedoke-McMaster stroke assessment and modified Barthel Index self-assessment in patients with vascular brain damage. Int J Rehab Res 2003;26:93-99.

6. Desrosiers J, Malouin F, Richards C, Bourbonnais D, Rochette A, Bravo G. Comparison of changes in upper and lower extremity impairments and disabilities after stroke. Int J Rehab Res 2003;26:109-116.

7. Cacho EWA, Melo FRLV, Oliveira R. Avaliação da recuperação motora de pacientes hemiplégicos através do Protocolo de Desempenho Físico de Fugl-Meyer. Revista Neurociências 2004,12:94-102. Errata 12: 221

8. Ferrucci L, Bandinelli S, Guralnik JM, et al. Recovery of functional status after stroke: a postrehabilitation follow-up study. Stroke 1993;24: 200-205.

9. Olsen TS. Arm and Leg paresis as outcome predictors in stroke rehabilitation. Stroke 1990;21:247-251.

10. Bohannon RW. Standing balance, lower extremity muscle strength, and walking performance of patients referred for physical therapy. Percept Motor Skills 1995;80:379-385.

11. Fugl-Meyer AR. Assessment of motor function in hemiplegic patients. In Bueger AA (ed). Neuropsychological aspects of rehabilitation medicine. Springfield: Charles C Thomas, 1976.

12. Garland SJ, Willems DA, Ivanova TD, Miller KJ. Recovery of standing balance and functional mobility after stroke. Arch Phys Med Rehabil 2003,84:1753-1759.

13. Duncan PW, Propst M, Nelson SG. Reliability of the Fugl-Meyer assessment of sensorimotor recovery following cerebrovascular accident. Phys Ther 1983;10:1606-1610.

14. Granger C, Hamilton B, Sherwin F. Guide for the use of the uniform data set for medical rehabilitation. Geneva: WHO, 1990.

15. Skilbeck CE, Wade DT, Langton-Hewer R, Wood VA. Recovery after stroke. J Neurol Neurosurg Psychiatry 1983;46:5-8.

16. Gowland C, VanHullenaar S, Torresin W, et al. Chedoke McMaster stroke assessment. Hamilton: Chedoke - McMaster Hospitals and McMaster University, 1995.

17. Karatas M, Cutin N, Bayramoglu M, Dilek A. Trunk muscle strength in relation to balance and functional disabilty in unihemisphere stroke patients. Am J Phys Med Rehabil 2004;83:81-87.

18. Di Fabio RP, Badke MB. Relationship of sensory organization to balance function in patients with hemiplegia. Phys Ther 1990;70:542-548.

19. Portney L, Watkins M. Foundation of clinical research: application to practice. Upper Saddle River: Appleton and Lange, 1993: 446-449.

20. Keeman MA, Perry JH, Jordan C. Factors affecting balance and ambulations following stroke. Clin Orthop 1984;182:165-171.

21. Horak FB. Clinical measurement of postural control in adults. Phys Ther 1987;67:1881-1885.

22. Bohannon RW. Determinants of transfer capacity in patients with hemiplegia. Physiother Can 1988;40:236-239.

23. Bohannon RW, Walsh S. Association of paretic lower extremity muscle strength and balance with stair climbing ability in patients with stroke. J Stroke Cerebrasvasc Dis 1991;1:129-133.

24. Juneja G, Czyrny JJ, Linn RT. Admission balance and outcomes of patients admitted for acute inpatient rehabilitation. Am J Phys Med Rehabil 1998;77:388-393.

25. Nichols DS, Miller L, Colby LA, Pease WS. Sitting balance: its relation to function in individuals with hemiparesis. Arch Phys Med Rehabil 1996;77:865-869.

26. Shepherd RB. Adaptive motor behavior in response to perturbations of balance. Physiother Theor Pract 1992;8:137-143.

27. Stevenson TJ, Garland SJ. Standing balance during internally produced perturbations in subjects with hemiplegia: validation of the balance scale. Arch Phys Med Rehabil 1996;77:656-662.

28. Dettmann MA, Linder MT, Sepic SB. Relationships among walking performance, postural stability, and functional assessment of the hemiplegic patient. Am J Phys Rehabil 1987;66:77-90. 